\title{
A PV System with MPPT Tracking and Off Demand Diverting Mechanism
}

\author{
Minu Theresa Mathew \\ University of Technology, Salmabad, Kingdom of Bahrain \\ mtmathew@utb.edu.bh
}

\begin{abstract}
Renewable energy resources and their implementation in the power sector will be the future of the upcoming world. The technology implementing PV cell and its use in the energy sector is growing in momentum nowadays. PV cell implemented along with MPPT tracking increases the efficiency of the energy system involved. A PV system with MPPT tracking and off Demand diverting mechanism is used in the prototype implemented. At On load the system can supply the load utilizing the MPPT. At night if the system has a battery, it can supply all the loads on demand. At less loading conditions, If the batteries are not discharged and if there is provision of irradiance then the MPPT cannot track the maximum power since there is no load to take it. So diversion of the power to allow MPPT tracking is done in the prototype to feed an additional load on demand. Simulations are done in mat lab and waveforms are analyzed.
\end{abstract}

Keywords: PV Cell, MPPT, Demand, Load

DOI: $10.7176 / \mathrm{JETP} / 11-6-04$

Publication date: November $30^{\text {th }} 2021$

\section{Introduction}

The demand for the renewable power energy system is exponentially increasing as the years pass by. PV cell popularity and its implementation is commonly seen in many industries as a replacement to the conventional power generation methodologies. One of the main advantages of using a PV system is that it doesn't pollute the ecosystem and the system itself is very quiet. The system is free of wear and tear and any errors can be easily tracked hence maintenance can be done easily. Because of the abundance of solar energy PV system can be employed even in a rural region. One of the main drawback of using PV cell is that inorder to provide subsequent power to the load a lot of stacking of PV cells are required, making it quite cumbersome. The average lifespan of a typical panel of solar cell is anywhere between 20 to 25 years. This makes the system quite efficient, in terms of initial cost.

Maximum power point tracking employed in a PV system makes it more efficient tracking the maximum power of the panel at any load. The output from the PV cell mainly depends on the irradiance factor as well as the load connected to the system (electrical characteristics). Depending on the solar irradiance the characteristic of load that gives maximum power changes where MPPT tracking comes into effect. It is the duty of MPPT to use an appropriate load to get the maximum power.

The PV system employed can be heated up in many circumstances owing to its overuse. The prototype mentioned in this paper will help in the elimination of overheating of PV modules and effective utilization of MPPT tracking making the system more efficient. Diverting of the power to the load helps to keep the MPPT functional making the system more synchronized. In physical models employed in practical applications the MPPT system comes along with the Solar panel. When simulations have to be implemented the MPPT has to be designed according to the requirements.

The area of research is in line with the research thrust of the university and is contributing to the society as it helps to improve the prototype design in the power generation schemes utilizing renewable energies.

\section{Statement of the Problem}

Maximum power point tracking mechanism in a PV model helps in the efficient utilization of PV Panels employed. The tracking of voltage which results in the generation of maximum power is done MPPT. MPPT is actually an algorithm by implementing of which the PV panel operates at it maximum efficiency. Since the system is based on renewable power supplies, the PV System is having immense popularity. One of the main problems of PV system is its working when the system is connected to a battery and the battery has not discharged yet. At this particular condition, if it is coupled with off load then the MPPT tracking or PV Panel cannot be used to its full 
efficiency which can result in over heating of the panel. The systems efficiency itself can droop down under these circumstances making the system fully operational during on load hours with sufficient irradiance and with a back up of a battery supply. This problem can be eliminated by the implementation of a off load specifically for this circumstances and other active loads can be operated when the system is fully functional. If this is implemented, The full usage of MPPT tracking can be acquired.

\section{Scope and Limitations}

The study is mainly focused on the development of a PV system with MPPT tracking which will be operational at all load hours. Since MPPT system is operational at all load hours the maximum power can be tracked at all load making the system fully functional with maximum efficiency. The main challenge in designing the system is not to make the system complex. The design with minimum set of requirements is always desirable. Another challenge is in the diverting of load to the off load mechanism.

\section{Literature Review}

According to researcher (Lazarov, Zarkhov, Stuyanov, \& Kanchev, 2013) as per two methods of MPPT methods studied which are fuzzy based MPPT and MPPT based on look up table the results were studied. The two MPPT models were implemented on a three phase and a single phase system. In three phase system 9KW peak was used, and in a single phase system $270 \mathrm{~W}$ peak was used. The results showed that the performance curves in the simulation was similar to experimental results.

According to researcher (Mohammad \& D, 2014) PV module implemented in the prototype is analyzed on characteristics like I-V and P-V. MSX 60 modules of PV were used for the simulation and the mppt model and the corresponding PV modules showed performances desired for the effective operation of the module. Simulation results showed that the characteristics I-V and P-V shows matching with the data sheet values. In the prototype boost converter topology is connected to the PV module. The output obtained from the PV module system like output current and output voltage shows extreme matching with the data in the data sheet.

According to the researcher (Dehedkar \& Vitthalrao Murkute, 2018), the paper discussed about MPPT control with the perturb and control method. The maximum power point is tracked with the help of irradiation and temperature. The distributed MPPT system is implemented to have an improved efficiency in the system. The maximum solar energy is tracked with the help of the perturb and control method.

As far as (Aouchiche, Aitcheikh, \& Becherif, 2018) is concerned the paper had a new proposal of DMPPT control and the performance of the system is analyzed in a $1 \mathrm{MW}$ PV model. The converter is controlled by DPMPPT control which is MFO based. According to this paper it overcomes any drawbacks due to mismatch phenomena. The prototype provides maximum efficiency. The prototype was found to be robust under the given conditions

According to researcher (Chyun Hsieh, Liang Chen, \& Yuan Chang, 2009), a PV system which is stand alone is implemented. The maximum power point tracking implemented in the prototype was incremental conductance based. The DC Converter employed in the circuit was a bidirectional DC-DC Converter. The system was also equipped with an energy management control mechanism as well. The prototype was found to be stable and could continuously and steadily supply the output power. The bidirectional converter plays a key role because it can adapt to any unstable energy coming from the photo voltaic system which is due to the changes in the load.

The works of researchers (Hong \& Li, 2010) deals with the design and implementation of a distributed Photovoltaic system which is stand alone. Parallel battery charger is used in the system which is the prototype. All the losses in the prototype were compensated in the prototype which makes the system quite efficient. A control logarithm was implemented for the operation of the MPPT system.

Concerning the works of (Manohar \& Sobha Rani, 2012), a grid connected PV employed with MPPT control is implemented. Voltage as well as current control is implemented in the matlab simulink model. Any sort of external faults within the system is corrected using the current control mechanism. The system efficiency and reliability as well as performance is improved as shown in the simulations obtained from simulink.

The researchers (Munir, Aldhanhani, \& Al Hosani, 2017) presented in their paper a grid connected photo voltaic system. An MPPT algorithm is implemented in the system to control the system as well as optimize the 
performance. A PI controller mechanism is also implemented to control the mppt as well as to control the switching operations in the converters and inverters implemented in the system. A single phase inverter was used to convert the DC voltage to AC and it was synchronized with the system using a phase locked loop methodology. The output of the system was found to be in analogy with the experimental outputs of the physical model.

The works of (Munteanu \& Bratcu, 2014) presented an MPPT system using extreme seeking control mechanism. There is no inclusion of intermediate conversion strategies using converters which work DC-DC. This non inclusion increases the efficiency of the system implemented. It utilizes the typical principles of AM modulation and demodulation. Considerable changes in the system performance were observed with the changes in the irradiance of the system. Excitation signals requirement were also considerable after noticing the system behavior. Wash out filter in the system was chosen as band pass filter instead of high pass filter owing to the increased performance of the system.

The researcher (Patil, Murkute, \& Bhombe, 2017) provides a system which can provide an effective MPPT tracking with high level of efficiency. A synchronous reference frame is implemented in the topology which provides control of the system. The adopted strategy was found to contain some drawbacks and need to be rectified. Changes in DC-DC boost converter topology was also to be adopted which provides constant voltage even with changes in the irradiance factor.

According to (Sankar, Velladurai, Rajarajan, \& Thulasi, 2017) a dual MPPT controller was implemented with the fuzzy logic controller. The first controller tracks the irradiance at different angles like azimuth, elevation etc. Second MPPT controller implemented controls the converter used in the system. The system was found to have stable operations throughout and oscillations were found to be minimized in this system.

The researchers (TahiriF.E, Chikh, Khafallah, Saad, \& Breuil, 2017) a PV system which is stand alone was implemented. AN MPPT algorithm was implemented along with a PWM inverter. The output shows that the output voltage remains constant irrespective of changes of the factors of irradiance or temperature of the PV Panel.

\section{Theoretical and Conceptual Framework}

The prototype to be implemented consists of a PV system with an MPPT control. The PV system consists of PV cells stacked together to form a PV array. The PV array generates a DC voltage. Inorder to boost this voltage a boost converter can be connected to the system, which can be further inverted to ac voltage with the help of an inverter. The inverter configuration is used because the load requirements are alternating voltage. There will be two loads connected to the system one the usual load at on demand and then there will be a secondary load connected for the enhancing of MPPT efficiency.

\subsection{PV Array}

For the PV array in mat lab, an equivalent circuit can be represented. The output of the array depends on the irradiance of the solar energy and the temperature. The output current of the circuit is represented as $\mathrm{I}_{\mathrm{M}}$.

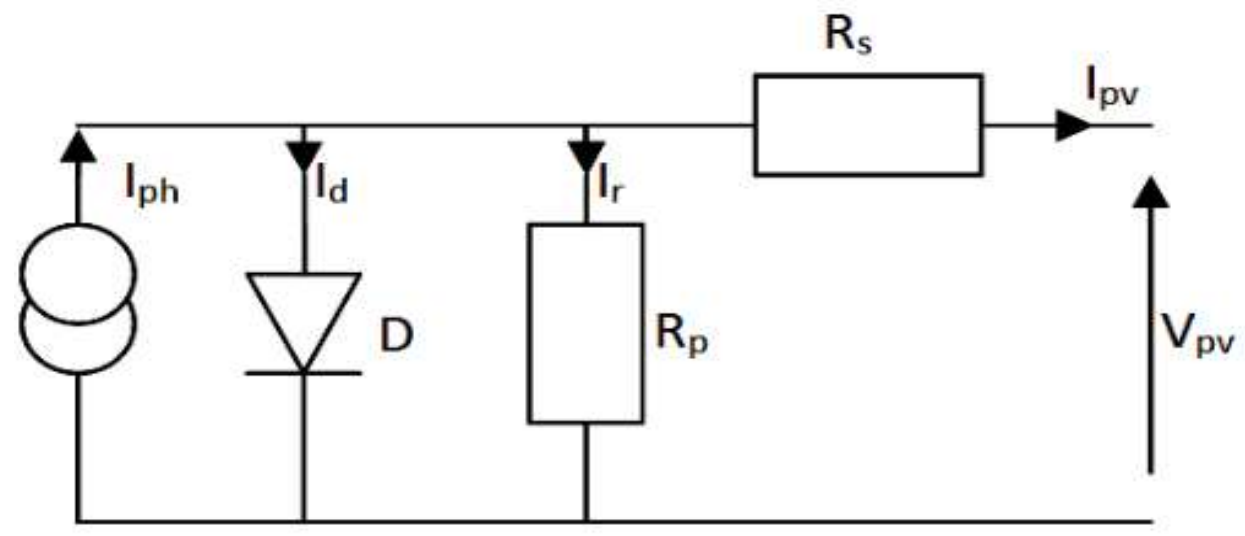

Figure 1: Circuit Diagram of a PV Cell

\subsection{Boost converter}

Inorder to increase the voltage produced from the PV array, a boost converter can be implemented. A typical model 
of the boost converter is given below.

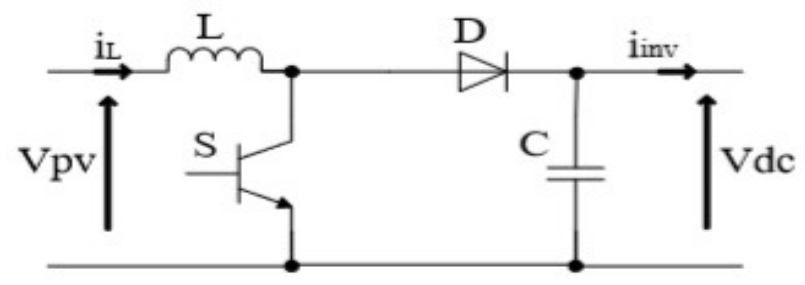

Figure 2: Boost converter configuration

If the analysis of the branches of the above circuit is done then we will obtain the set of equations given below

$$
\mid \begin{aligned}
& \frac{d i_{L}}{d t}=\frac{1}{L_{b}}\left[V_{b i}-(1-d) V_{D C}\right] \\
& \frac{d V_{D C}}{d t}=\frac{1}{C_{D C}}\left[(1-d) i_{L}-i_{i n v}\right]
\end{aligned}
$$

In the equation given above, $\mathrm{i}_{\mathrm{L}}$ is the input current to the circuit, $\mathrm{L}_{\mathrm{b}}$ is the inductance. $\mathrm{d}$ is the state of switching. The second set of equations represents the output voltage of the configuration. $\mathrm{V}_{\mathrm{DC}}$ is the output voltage and $\mathrm{C}$ represents the capacitance connected at the output side.

\subsection{PWM Inverter}

A PWM inverter can be used to convert the DC voltage to ac voltage. A three phase PWM inverter is used which can give a fixed output, say more than $350 \mathrm{~V}$. This output voltage from the PWM inverter does not depend on the load connected to the circuit.

The PWM inverter produces a pure sinusoidal wave with reference to a square wave and can be used to obtain an alternating voltage.

PWM inverter consist of pulse generator, switching device, driver circuit Frequency of the signal is given as $\mathrm{F}=1.30 / \mathrm{R}_{\mathrm{T}} \mathrm{R}_{\mathrm{C}}$

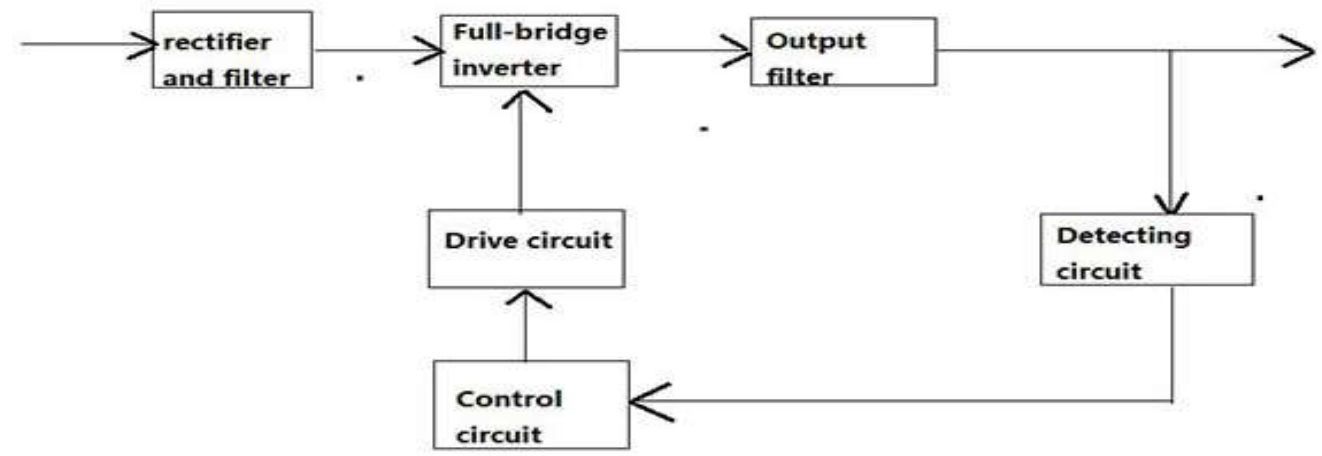

Figure 3: Block diagram of 3 Phase PWM Inverter Circuit

As shown in the block diagram given in the input side there is a rectifier and a filter circuit. Connected to the rectifier and filter is the full bridge inverter which is driven by a driver circuit. The detecting and control circuit controls the driver circuit. The final output is connected to the load through an output filter circuit. 


\subsection{Block diagram of PV System with MPPT and load diverting}

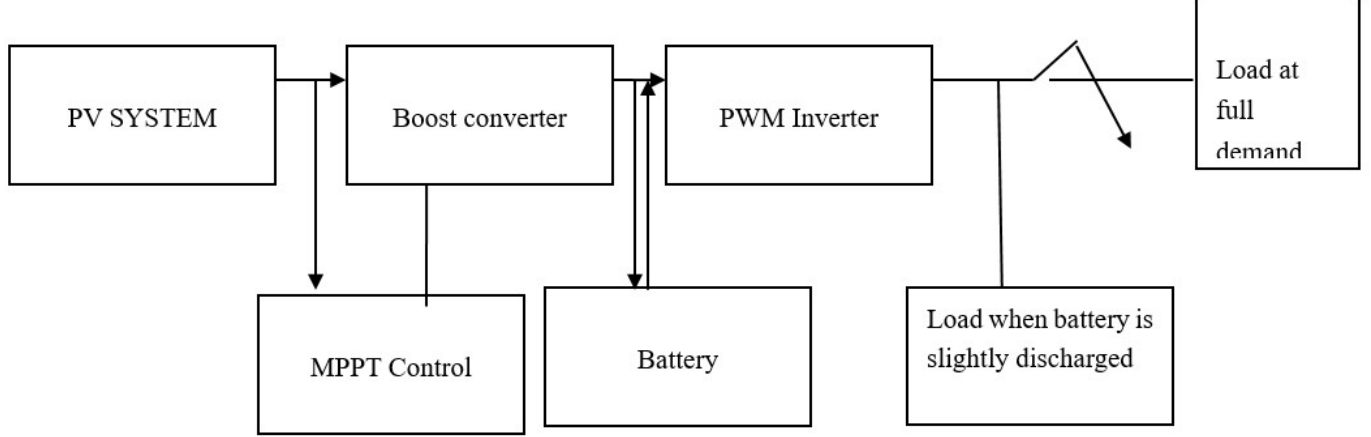

Figure 4: Block diagram of Proposed PV Model

In the block diagram mentioned above a PV array is connected to a boost converter topology and MPPT control. The output of the PV array is fed to the battery system. The battery also feeds the load which is connected at the output side. The DC output of the battery and converter is converted to ac using a PWM inverter. This conversion is done since the load is an ac load. The load connected is divided into two. One load is for full demand hours and other load is when the battery connected is slightly discharged. By implementing this dual load connection as shown above the utilization of MPPT can be maximized and any losses can be compensated. This increases the efficiency of the system as well.

MPPT control which can be adopted is constant voltage or current sweep method. This method can be easily implemented in the system adopting the appropriate strategies.

\subsection{PV System Model Design with MPPT Control}

The PV system implemented uses a maximum power point tracking mechanism.

The solar panel effective output from each subsystem is given as Vmpp $=336 \mathrm{~V}$, Voc $=406 \mathrm{~V}$.

The irradiance constant selected for the PV System is taken as 100. The PV cell basic system is modeled with a current controlled source, diode and resistor connected in parallel combination.

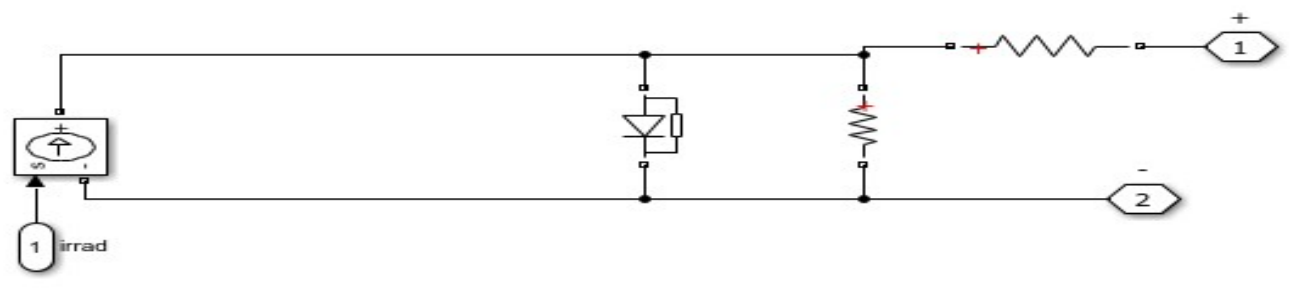

Figure 5: PV cell basic Sub system model

Current gain is applied to the basic solar cell subsystem to increase the output voltage of the system

Figure 6: PV System- System -2 


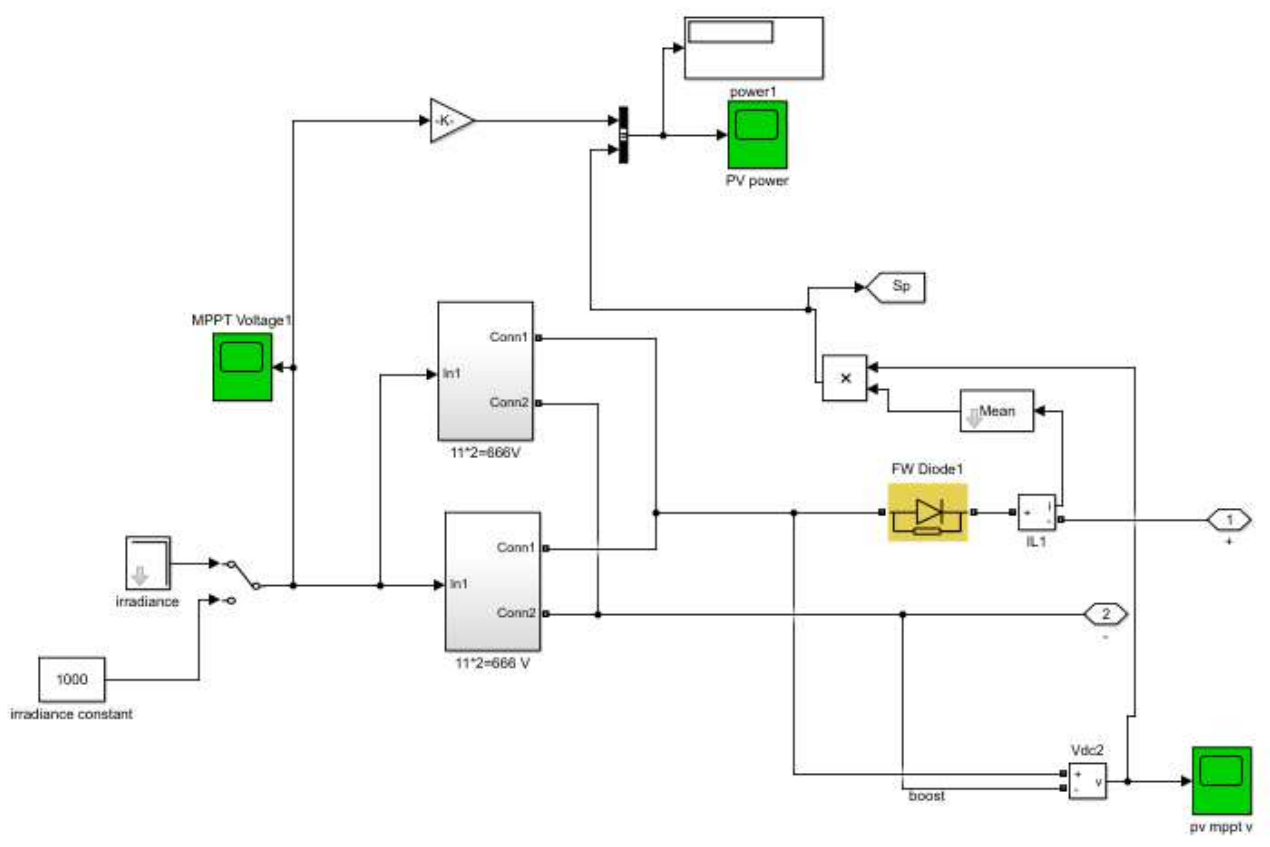

Figure 7: PV System Full Model

Two sub systems are used in the Photo Voltaic system each having $666 \mathrm{~V}$ with an irradiance factor of 1000 . A freewheeling diode is also connected across the PV system combination to disconnect the output from the PV system when not desired.

\subsection{Battery and DC-DC Boost converter}

The converter used in the system is a boost converter which boosts the voltage before being given to the battery system and also to the inverter. The battery connected to the system is a Nickel-Metal hydride type battery with Nominal voltage of $300 \mathrm{~V}$.

The following are the other parameters of the battery

Rated capacity in $\mathrm{Ah}=6.5 \mathrm{Ah}$

Initial state of charge in percentage $=60 \%$

Battery response time $=30$ seconds

Maximum capacity $=7 \mathrm{Ah}$

Cut off Voltage $=225 \mathrm{~V}$

Fully Charged Voltage $=353.59 \mathrm{~V}$

Nominal Discharge Current $=1.3 \mathrm{~A}$

Internal Resistance $=0.46 \mathrm{ohms}$

Capacity in Ah at the Nominal voltage $=6.25 \mathrm{Ah}$ 


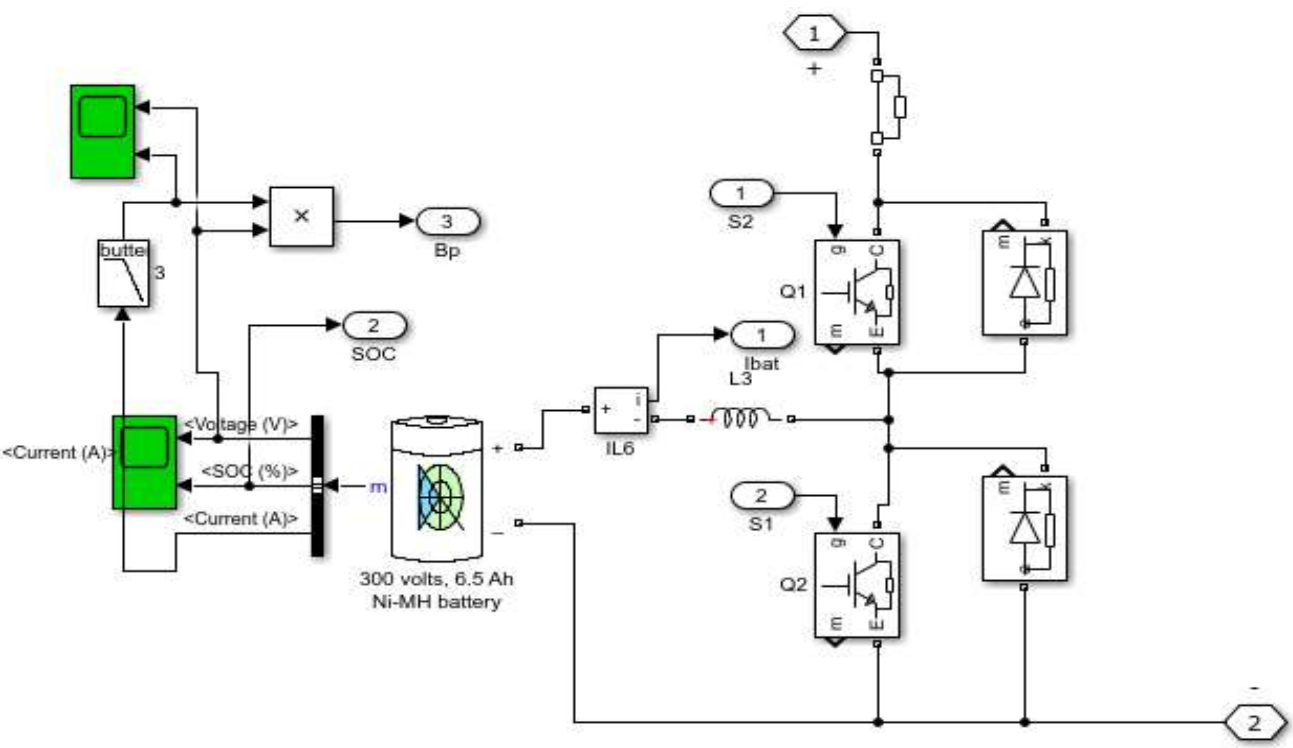

Figure 8: Battery with DC-DC Boost Converter

\subsection{PWM Inverter}

A PWM IGBT inverter which has a universal model is adopted as an inverter model. An inverter circuit implemented here converts the Direct current voltage to a three phase ac voltage. LC-filters are also connected at the output of the inverter circuit to filter out unwanted signals which are not desired. The number of bridge arms used in the PWM inverter is 3 to develop three phase AC voltage.

The Snubber resistance of the model is selected to be $5000 \mathrm{ohms}$, since a series RC Snubber circuits are connected in shunt with each of the IGBT Switching device. A $300 \mathrm{~V}$ output AC Voltage is desired at the output of the device.

\subsection{Load connected at Full demand/ Load at diverting}

The PV system is connected to the grid at full demand which will be indicated as a three phase RLC load with parallel y grounded load.

The following are the parameters of the load connected

Nominal Phase to Phase Voltage, RMS Voltage $=385 \mathrm{~V}$

Nominal Frequency $=50 \mathrm{~Hz}$

Active Power of the Load $=1000 \mathrm{~W}$

\subsection{Method of Analysis}

The analysis will be done on the PV system incorporated with the MPPT control. The model is developed with the help of Matlab Simulink Software. The analysis of the output waveforms of the PV system, Inverter and Load will be done. On the basis of the output obtained and analysis, the Matlab simulink model can be improved. 


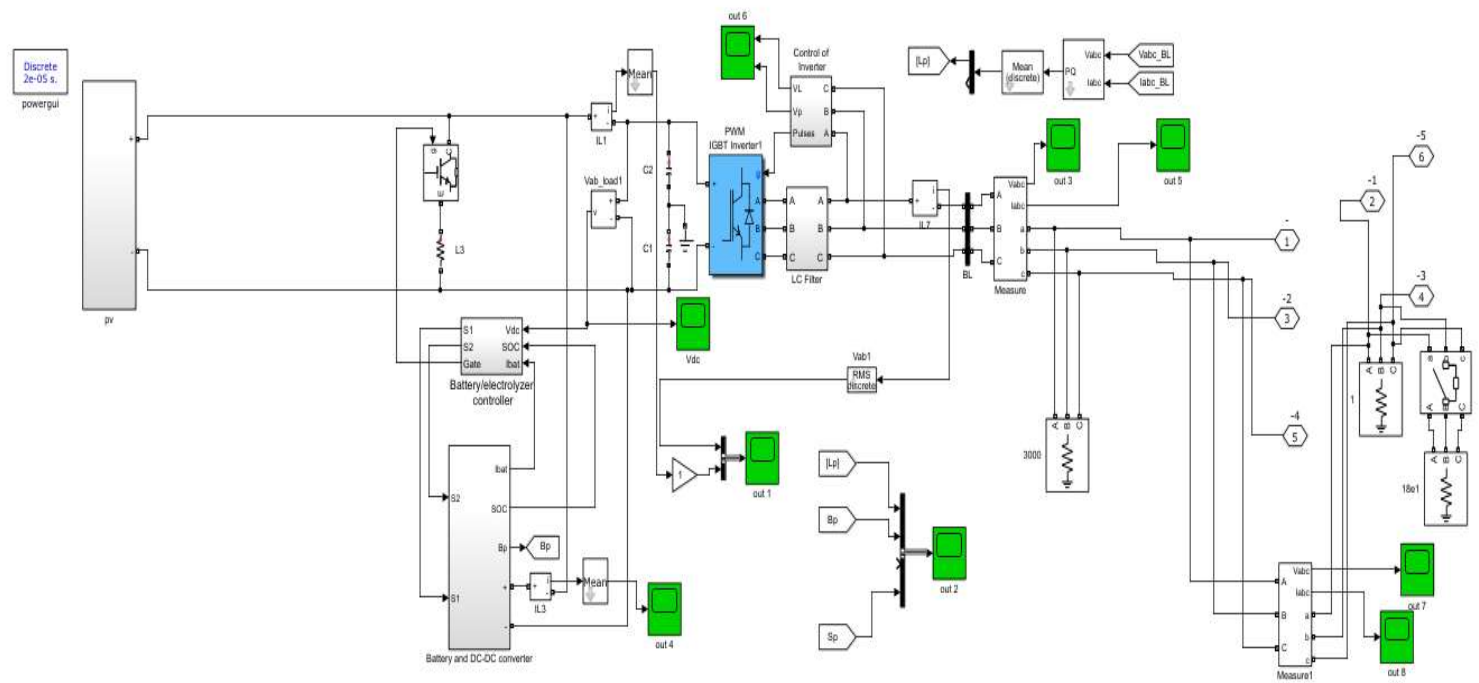

\subsection{Output Current across the load}

File Tools View Simulation Help

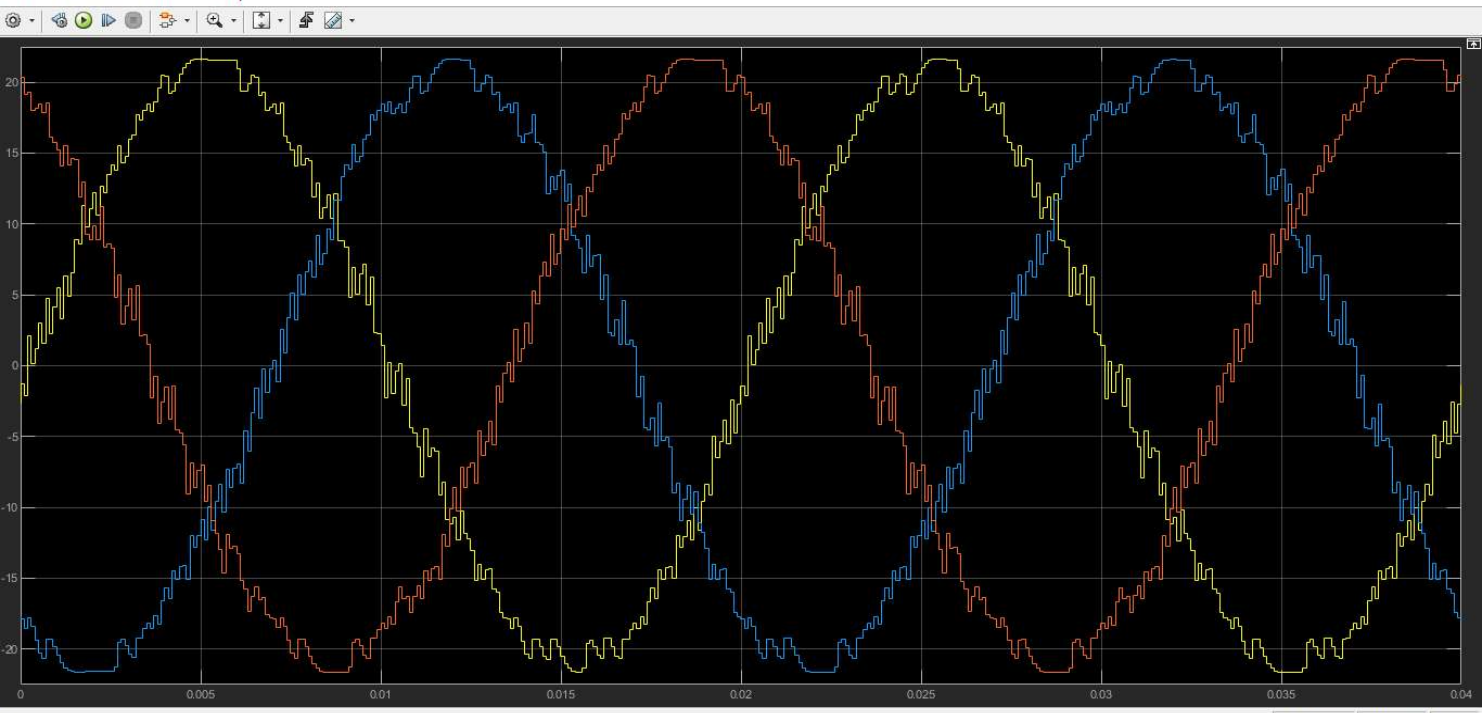

The output current is found to be a 3 phase current since the load is a three phase load. The magnitude of current was found to be around 25 Ampere. The output current is found to have harmonic component present which can be smoothened by the implementation of smoothening filter circuit. An LC filter circuit was implemented at the output of the inverter which reduces harmonics to a significant level but further smoothening can be done with appropriate and complex filters. 


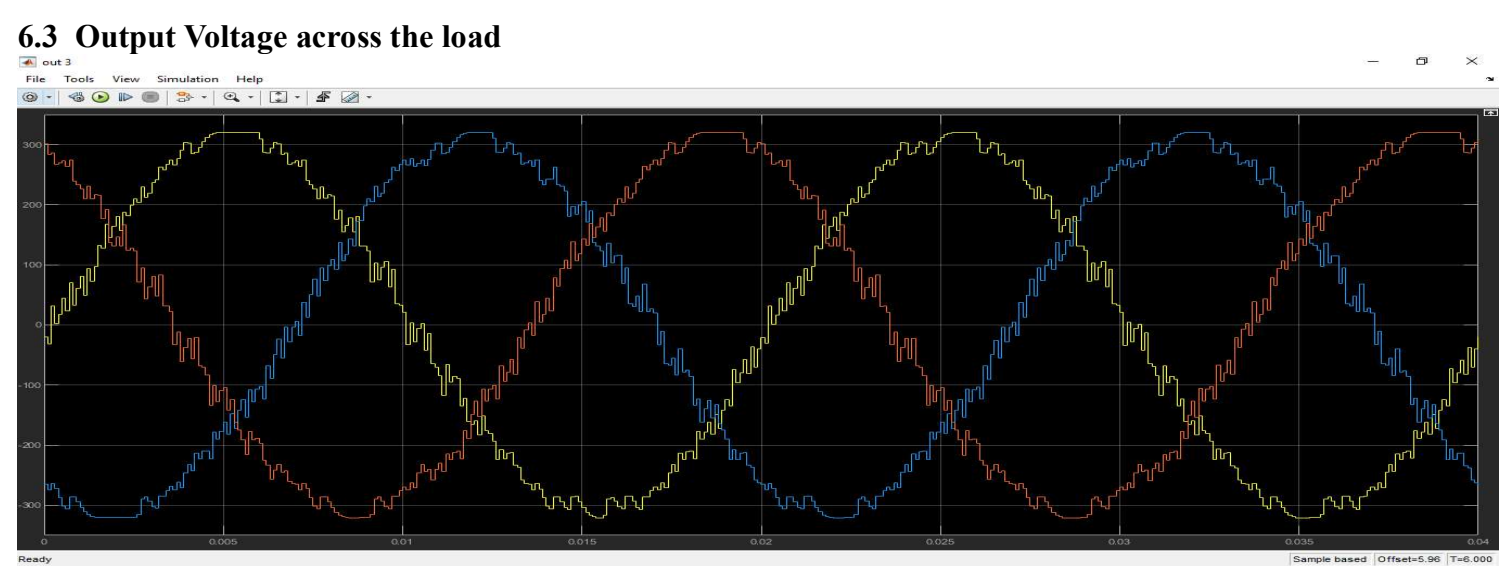

The output voltage across the load which is at full load is given above. The amplitude of the voltage was found to be around $350 \mathrm{~V}$ and the voltage is a three phase voltage since the load connected is a three phase load.

\section{Conclusion}

On the basis of the output obtained it can be concluded that the voltage across the power generation system can be modelled as per the load requirements and depending upon the demand the system can be remodeled as per the requirements. The efficiency of the solar MPPT model can be maximized with the incorporation of the on load and off load as connected.

\section{References}

Lazarov, V. D., Zarkhov, Z., Stuyanov, L., \& Kanchev, H. (2013). Grid Connected PV System with MPPT Control., (pp. 357-366). Sofia.

Mohammad, S. S., \& D, D. (2014). Simulation and Analysis of Stand-alone Photovoltaic System with Boost Converter using Matlab/Simulink. 2014 International Conference on Circuit, Power and Computing Technologies [ICCPCT], (pp. 814-821).

Dehedkar, M. N., \& Vitthalrao Murkute, S. (2018). Optimization of PV System using Distributed MPPT Control. Proceedings of the SMART-2018, IEEE Conference ID: 44078 (pp. 216-220). Moradabad, India: 2018 International Conference on System Modeling \& Advancement in Research Trends.

Aouchiche, N., Aitcheikh, M. S., \& Becherif, M. (2018). AI-based global MPPT for partial shaded grid connected PV plant via MFO approach. Science direct, Solar energy, 594-603.

Chyun Hsieh, G., Liang Chen, H., \& Yuan Chang, C. (2009). Energy Management for Interleaved PV Stand-Alone System with Incremental Conductance MPPT . IEEE CONFERENCE PROCEEDINGS, (pp. 1-6).

Hong, W., \& Li, B. (2010). The Cooperated MPPT Control of Stand-alone PV Power Generation System. Proceedings of the 8th World Congress on Intelligent Control and Automation, (pp. 2229-2231). China.

Manohar, K., \& Sobha Rani, P. (2012). Mppt and Simulation for a Grid-Connected Photovoltaic System and Fault Analysis. The International Journal of Engineering, 158-166.

Munir, M. I., Aldhanhani, T., \& Al Hosani, K. H. (2017). Control of Grid Connected PV Array using P\&O MPPT Algorithm. 2017 Ninth Annual IEEE Green Technologies Conference, (pp. 52-58).

Munteanu, I., \& Bratcu, A. I. (2014). MPPT for grid-connected photovoltaic systems using ripple-based Extremum Seeking Control: Analysis and control design issues. Science direct, Solar energy, 30-42.

Patil, S. G., Murkute, H., \& Bhombe, R. (2017). Single Phase Grid Connected PV System Using MPPT Converter. International Conference on Science and Engineering for Sustainable Development, (pp. 87-93).

Sankar, R., Velladurai, S., Rajarajan, R., \& Thulasi, J. (2017). Maximum Power Extraction in PV System using Fuzzy Logic and Dual MPPT Control . International Conference on Energy, Communication, Data Analytics and Soft Computing, (pp. 3764-3769).

TahiriF.E, Chikh, K., Khafallah, M., Saad, A., \& Breuil, D. (2017). Modeling and performance analysis of a solar PV power system under irradiation and load variations. 2017 14th International Multi-Conference on Systems, Signals \& Devices (SSD), (pp. 234-238). 